\title{
COMISIONES DE LA VERDAD Y LOS DERECHOS HUMANOS: UN PUENTE HACIA LA RECONCILIACIÓN Y LA REINTEGRACIÓN SOCIAL COLOMBIANA
}

\author{
Berónica Narváez Mercado ${ }^{1}$ \\ Adelaida María Ibarra Padilla ${ }^{2}$ \\ Jairo Alcides Aguas Fernández ${ }^{3}$
}

\section{Resumen}

El Desarme, Desmovilización y Reintegración- DDR y la justicia transicional- JT han tenido tradicionalmente un abordaje desarticulado por considerar que atienden a poblaciones y objetivos diferentes. Este artículo sostiene la necesidad de acercar estos dos campos y que el principal punto de convergencia lo constituyen las comisiones de la verdad. Estas comisiones son un espacio en el que todos los actores del conflicto: víctimas, perpetradores y demás miembros de la sociedad, participan en la construcción de la memoria colectiva de un pasado de violencia. Este estudio analiza las características de estas comisiones, quiénes participan en ellas y sus limitaciones. Por último concluye que las comisiones de la verdad son la muestra de que el abordaje conjunto de DDR y JT contribuye tanto a la reparación de las víctimas como a la reintegración de excombatientes al tiempo que contribuye a alcanzar la reconciliación social.

1 Doctorante en Derecho de la Universidad Libre de Colombia. MBA de la Escuela Libre de Derecho de Costa Rica, Abogada, Conciliadora y Docente Investigadora, Directora del Centro de Investigaciones Sociojurídicas de la Facultad de Derecho y Ciencias Políticas de la Corporación Universitaria del Caribe, Líder del Grupo de Investigación GISCER. Email: beronica.narvaez@cecar.edu.co

2 Doctora en Derecho (Universidad de los Andes), Magíster en Derecho Internacional (Universidad de los Andes), MBA en Gestión Sostenible (Universität Leuphana Lüneburg, Alemania), Magíster en Derecho (Universidad del Norte), Abogada (Universidad del Atlántico). Docente Investigadora, Corporación Universitaria Americana. Email: halloadela@hotmail.com

${ }^{3}$ Abogado Especialista en Derecho Contencioso Administrativo, Universidad Externado de Colombia. Email: jafer0752@hotmail.com 
Palabras Clave: Comisión de la verdad, justicia transicional, reintegración, víctimas, excombatientes.

\begin{abstract}
Disarmament, Demobilization and Reintegration (DDR) and transitional justice (JT) have traditionally had a disjointed approach, considering that they are targeting to different populations and objectives. This article supports the need to bring these two fields closer together and that their main point of convergence are truth commissions. These commissions are a space in which all the actors of the conflict: victims, perpetrators and other members of society, participate in the construction of the collective memory of a past of violence. This study analyzes the characteristics of these commissions, their participants, and the limits they have. Finally, it concludes that truth commissions are proof that the joint approach of DDR and JT contributes both to the reparation of victims and the reintegration of ex-combatants while contributing to achieve social reconciliation.
\end{abstract}

Keywords: Truth commission, transitional justice, reintegration, victims, former combatants.

\title{
Introducción
}

A unque el Desarme, Desmovilización y Reintegración- DDR y la justicia transicional tienen lugar simultáneamente, a menudo no en los extremos del debate paz vs justicia. Sobre el particular, la Corte constitucional colombiana señaló que la reducción del derecho a la justicia, como instrumento para la realización de la paz, puede ser un medio para hacer efectivos los derechos de las víctimas a la no repetición en la medida en que cesa el conflicto armado. Esta reducción contribuye aún más a la verdad si los que se desmovilizan revelan la conducta criminal cometida; y a la reparación si el proceso de desmovilización establece reglas que lleven a los combatientes desmovilizados a satisfacer los derechos de las víctimas.

A medida que los enfoques del DDR y la justicia transicional se han ido expandiendo, estos dos campos se superponen en algunos puntos. La participación de los excombatientes en los procesos de justicia transicional, como los juicios de transición, las comisiones de la verdad y los instrumentos de justicia basados en la cultura, es cada vez más común. Del mismo modo, la justicia transicional se refiere cada vez más al DDR para 
comparar los beneficios que proporciona a los excombatientes con los ofrecidos a las víctimas (Sriram et al., 2013, p.9).

Este estudio se ocupa de las comisiones de la verdad como el principal punto de convergencia entre ellos y la manera de acercarlos. La participación de los combatientes desmovilizados en las comisiones de la verdad puede beneficiar no solo a las víctimas sino también mejorar el proceso de reintegración. Por un lado, las víctimas encuentran las respuestas a sus preguntas, lo que alivia su sufrimiento y, por lo tanto, es parte de su reparación. Por otro lado, los perpetradores manifiestan implícitamente su arrepentimiento y su deseo de ser aceptados nuevamente en la sociedad a través de sus declaraciones públicas (Shibuya, 2012, p.108).

En primer lugar se analiza desde una perspectiva histórica como el DDR y la Justicia Transicional han tenido un desarrollo paralelo pero separado y como a medida que ambos campos se amplían sus puntos de convergencia son mayores. Se estudia luego como a partir de la desmovilización de las autodefensas en Colombia, el tema de la reintegración de excombatientes empieza a ser condicionado a la reparación de las víctimas evidenciado el entrelazamiento de entre DDR y JT. Seguidamente se aborda el tema de la verdad como un derecho no sólo de las víctimas sino de la sociedad en su conjunto y como las comisiones de la verdad son en sí mismas una forma de reparación. Sin embargo, también se señalan sus condicionantes y limitantes. Se plantea la necesidad de incluir más voces que tradicionalmente quedan acalladas con el fin de que sirvan de medio para alcanzar una reconciliación social más amplia.

\section{Justicia transicional y DDR: historias separadas que se acercan con el tiempo}

El Informe del Secretario General de Naciones Unidas de 2004 The Rule of Law and Transitional Justice in Conflict and Post-Conflict Societies y luego el UN-IDDRS (2006) define justicia transicional como:

Medidas utilizadas por una sociedad para lidiar con un legado de abusos contra los derechos humanos a gran escala a fin de la rendición de cuentas, servir a la justicia y lograr la reconciliación. Las medidas de justicia transicional incluyen respuestas judiciales 
y no judiciales, como enjuiciamientos, comisiones de la verdad, programas de reparación para las víctimas y herramientas para la reforma institucional, como la investigación. Cualquiera que sea la combinación elegida debe estar de acuerdo con los estándares y estándares legales internacionales.

Los procesos de transición se pueden clasificar según la forma como han resuelto las tensiones entre la justicia y la paz en cuatro tipos básicos: in- dultos amnésicos, perdones compensatorios, perdones responsables y transiciones punitivas. Los perdones amnésicos no contemplan la verdad ni reparar a las víctimas. Los perdones compensatorios van acompañados de la implementación de comisiones de la verdad y algunas medidas correctivas para las víctimas. Los perdones responsabilizantes implican el establecimiento de una comisión de la verdad, el requisito de la confesión total de crímenes atroces, algunas reparaciones y la concesión de indultos individuales. Las transiciones punitivas implican el establecimiento de tribunales ad hoc para castigar a los responsables de crímenes de guerra y crímenes de lesa humanidad (Uprimny et al., 2006, p.23).

Los procesos de transición también se clasifican de acuerdo con sus enfoques de reconciliación en justicia transicional reparativa o retributiva. Así, las comisiones de verdad y reconciliación, como las de Sudáfrica, Liberia, Perú o Guatemala, donde el compromiso de reconciliación se hizo mediante la verdad, el diálogo y la reparación, sin implicar necesariamente medidas punitivas, son un ejemplo de justicia transicional restaurativa. Por otro lado, tribunales especiales como los implementados en la antigua región de los Balcanes, la República Democrática del Congo, Camboya o Sierra Leona que persiguieron la reconciliación mediante el castigo constituyen un ejemplo de justicia retributiva (Grasa y Mateos, 2014, p. 49).

Se debe reconocer que el marco jurídico internacional con respecto a DDR y JT ha cambiado en el pasado reciente. En sus primeras etapas, las experiencias de DDR se caracterizaron por la concesión de amnistías, considerada entonces condición necesaria para lograr la paz. La justicia transicional, por su parte, no se enfocó en la reparación de las víctimas ni en 
esclarecer la verdad, sino en juicios ejemplares de los máximos responsables, olvidando la mayor parte de los combatientes y las necesidades de las víctimas.

Durante su primera fase, la justicia transicional se orientó hacia el castigo retributivo por violaciones a los derechos humanos. El Tribunal Militar Internacional de Núremberg, a diferencia de otros procesos transitorios llevados a cabo por regímenes sucesores, se caracterizó por estar dirigido por un grupo de potencias internacionales y no por un gobierno interno posterior. Por otro lado, las acusaciones eran de naturaleza híbrida, mezcla de aspectos relacionados con crímenes de guerra y lo que luego se denominó crímenes de lesa humanidad (Teitel, 2003).

En su segunda fase, los dilemas inherentes a los períodos de cambio político aumentaron la tensión entre el castigo y la amnistía. El movimiento por la verdad y la reconciliación tendió a evitar juicios y, en cambio, apuntó a ir más allá de las nociones legales de culpa y responsabilidad. En esta etapa, lo justo y equitativo en circunstancias políticas extraordinarias se determinó a partir de la posición transicional misma.

Muchos de los actores e instituciones relevantes estaban fuera del ámbito del derecho y la política, como iglesias, ONG y grupos de derechos humanos que incorporaron una amplia gama de alternativas en la resolución de conflictos. Correspondientemente a esta fase están la caída de los regímenes militares en América del Sur y las transiciones posteriores a 1989 en Europa del Este, África y América Central (Teitel, 2003, p.15).

La tercera fase inicia en los noventas con la creación de los tribunales internacionales especiales para la ex Yugoslavia y Ruanda, basados en el Capítulo VI de la Carta de las Naciones Unidas y después de un voto favorable del Consejo de Seguridad. En esta fase, la justicia transicional se desplaza hacia el Derecho Internacional de Derechos Humanos. Es un retorno a la justicia retributiva, al enjuiciamiento y castigo de los principales líderes, a la idea de que no es posible construir la paz con impunidad. Sin embargo, no termina allí y tambiéncontempla medidas de justicia restaurativa.

En este último aspecto, la Corte Interamericana de Derechos Humanos ha jugado un papel muy importante al sostener que la verdad era parte 
fundamental de la reparación e incorporara en sus sentencias medidas conducentes a la garantía de no repetición. En esta etapa, la Corte Penal Internacional se crea sobre una base permanente. El Estatuto de Roma (1998) representa la materialización del límite a la justicia transicional al incorporar un modelo legal que permite a la comunidad internacional representada en la Corte Penal Internacional y de conformidad con el principio de complementariedad, investigar y castigar a los responsables de graves violaciones de los derechos humanos (Teitel, 2003, p.22).

En Colombia, la primera norma de justicia transicional propiamente dicha fue la Ley 975 (2005) conocida como Ley de Justicia y Paz, que estableció un castigo alternativo de 5 a 8 años de prisión bajo la condición de decir la verdad y reparar a las víctimas. El Ministerio del Interior y Justicia lleva un registro de los miembros desmovilizados de grupos ilegales que desean beneficiarse de la ley.

De estas listas, el Gobierno designa a los desmovilizados que cumplen con los requisitos del Artículo 11 de la Ley 975 de 2005. Los desmovilizados designados deben presentar versiones libres de los fiscales de la jurisdicción de Justicia y Paz. Se requiere una confesión completa de los crímenes en los que participó cada desmovilizado. Existe la posibilidad de ser excluido del proceso si hacen confesiones parciales.

La Ley de Justicia y Paz consagró en su artículo 7 la verdad como un derecho inalienable que la sociedad y especialmente las víctimas tienen a conocer sobre los crímenes cometidos por grupos armados organizados, y el paradero de las víctimas de secuestro y desaparición forzada.

Asimismo, la Ley 1424 de 2010 condicionó los beneficios legales para los combatientes desmovilizados a la suscripción del Acuerdo de Aporte a la $V$ erdad y la Reparación, así como su vinculación al proceso de reinserción social y económica que brinda el Gobierno Nacional. 


\section{Tabla 1. DDR y Justicia Transicional}

\begin{tabular}{|c|c|c|}
\hline & DDR & Justicia Transicional \\
\hline $\begin{array}{c}\text { Grupo } \\
\text { beneficiario }\end{array}$ & $\begin{array}{l}\text { Excombatientes y sus } \\
\text { familias }\end{array}$ & Víctimas del conflicto armado \\
\hline Objetivos & $\begin{array}{l}\text { Contribuir a la se- } \\
\text { guridad y la estabilidad } \\
\text { en entornos de poscon- } \\
\text { flicto para dar lugar a la } \\
\text { recuperación y el desa- } \\
\text { rrollo. }\end{array}$ & $\begin{array}{l}\text { Facilitar la rendición de cuen- } \\
\text { tas, servir a la justicia y lograr la } \\
\text { reconciliación. }\end{array}$ \\
\hline $\begin{array}{l}\text { Compo- } \\
\text { nentes }\end{array}$ & $\begin{array}{l}\text { Desarme, desmovi- } \\
\text { lización, reinserción, re- } \\
\text { integración. }\end{array}$ & $\begin{array}{l}\text { Esclarecimiento de la verdad, } \\
\text { justicia, reparación, garantía de } \\
\text { no repetición. }\end{array}$ \\
\hline Medidas & $\begin{array}{l}\text { Auxilio de reinser- } \\
\text { ción, auxilio económico } \\
\text { mensual por un deter- } \\
\text { minado período, acom- } \\
\text { pañamiento psicoló- } \\
\text { gico, alfabetización } \\
\text { programas de valida- } \\
\text { ción del bachillerato, } \\
\text { cursos de formación } \\
\text { para el trabajo, proyec- } \\
\text { tos productivos, micro- } \\
\text { créditos. }\end{array}$ & $\begin{array}{l}\text { Juicios, comisiones de la } \\
\text { verdad, } \\
\text { programas de la reparación de las } \\
\text { víctimas (asistencia, compensa- } \\
\text { ción, rehabilitación y satisfac- } \\
\text { ción), reforma institucional. }\end{array}$ \\
\hline
\end{tabular}

Fuente: Configuración propia.

El acuerdo final de paz entre el gobierno y las FARC-EP creó el Sistema Integral de Verdad, Justicia, Reparación y No Repetición; tres de sus mecanismos están estrechamente relacionados con el deber de verdad de los excombatientes: 1) Comisión para la Clarificación de la Verdad, la Convivencia y la No Repetición. 2) Unidad especial para la búsqueda de personas desaparecidas en el contexto y por razón del conflicto armado. Y 3) Jurisdicción Especial para la Paz. En este mismo sentido, la Ley 1820 de 2016, que otorga amnistía a ex miembros de las FARC-EP por delitos políticos o conexos, también está condicionada a un testimonio veraz. 
La Comisión para la Clarificación de la Verdad, la Convivencia y la No Repetición (CEV) fue creada por el Decreto 588 de 2017 como un órgano extrajudicial cuyas actividades no tienen carácter judicial ni pueden servir para el enjuiciamiento penal ante ninguna autoridad jurisdiccional. La información recibida o producida por la comisión no puede ser transferida a las autoridades judiciales para asignar responsabilidades en procedimientos judiciales, ni las autoridades judiciales pueden exigirla. Sin embargo, la CEV puede solicitar a los magistrados, jueces y organizaciones de investigación la información requerida para el cumplimiento de su mandato. Aunque este decreto establece que los esfuerzos de la CEV se centrarán en garantizar la participación de las víctimas del conflicto, asegurando su dignidad y contribuyendo a la satisfacción de su derecho a la verdad (Artículo 5). El decreto también establece como uno de sus mandatos esclarecer y promover el reconocimiento del impacto del conflicto en aquellos que participaron directamente en él como combatientes y en sus familias y entornos (Artículo 11).

\section{La reintegración de excombatientes y su condicionamiento a la reparación}

Como resultado del Acuerdo de Ralito, el gobierno Uribe presentó al Con- greso en 2003 el proyecto de ley denominado Ley de Alternatividad Penal. Este proyecto de ley establecía la suspensión condicional de la ejecución de la pena impuesta a los miembros de grupos armados ilegales a favor de los intereses de la paz nacional a solicitud exclusiva y discrecional del Pre- sidente de la República (artículo 2). El documento no hizo distinción entre comandantes, niveles medios o soldados de base, ni entre delitos menores y crímenes de lesa humanidad. Este proyecto de ley fue fuertemente criti- cado por amplios sectores de la sociedad, incluidos los partidos políticos, las asociaciones de víctimas, las ONG y la comunidad internacional, tras considerar que favorecía la impunidad y no garantizaba los derechos de las víctimas a la verdad, la justicia y la reparación. Esta oposición de los acto- res locales y la presión ejercida por la comunidad internacional llevaron al gobierno a retirar el proyecto.

La Ley de Alternatividad Penal estaba muy en línea con lo que podría llamarse la institucionalización de un tipo de amnesia 
colectiva que se dio en el país a través de las amnistías y perdones y la ausencia de juicios y procesos o comisiones de la verdad a mediados de la década de 1980 (...) Este fue el mismo trato que se les ofreció originalmente a los paramilitares. (Restrepo, 2012, p.154)

El Proyecto de Ley de Alternatividad Penal fue seguido por la llamada Ley de Justicia y Paz que fue aprobada en julio de 2005. Esta Ley (Ley 975 de 2005) preveía una pena máxima de ocho años de prisión para los desmo- vilizados condicionados a que dijeran la verdad y compensarán a las vícti- mas. En octubre del mismo año, se creó la Comisión Nacional de Repara- ción y Reconciliación (CNRR). Su misión consistía en ejercer la vigilancia y el control del proceso de reintegración, garantizar la desmovilización to- tal de los grupos armados y evaluar la reparación y la restitución de las víctimas.

El Acuerdo Final de paz firmado en noviembre de 2016 entre el gobierno colombiano la guerrilla de las FARC y ratificado luego por el Congreso, por su lado, contiene muchos aspectos en materia de DDR que ya venían implementándose con los grupos armados desmovilizados tales como beneficios económicos, formación para el trabajo, afiliación al seguridad social y salud. Sin embargo, hay varios aspectos que son nuevos en este proceso transicional, especialmente el énfasis en que se conozca la verdad y la rendición de cuentas. Para ello el acuerdo contempla la creación de un Sistema integral compuesto por la Comisión para el Esclarecimiento de la Verdad, la Convivencia y la No Repetición; la Unidad para la Búsqueda de Personas dadas por Desaparecidas en el contexto y en razón del conflicto armado; la Jurisdicción Especial para la Paz; las medidas de reparación integral para la construcción de paz y las garantías de no repetición.

\section{La verdad como derecho, mecanismo de reparación y reconciliación}

El derecho a la verdad es una condición necesaria para el ejercicio de otros derechos como el derecho a la reparación y a la justicia (Benavides, 2011, p.43). 
Este derecho se materializa a través de diferentes formas como juicios dentro de la jurisdicción ordinaria, juicios dentro de la justicia transicional, mecanismos de rendición de cuentas, comisiones de la verdad, o a través de entidades públicas o privadas creadas para este propósito.

En el caso de Colombia, el deber de establecer la verdad ha estado a cargo del Centro Nacional de Memoria Histórica creado mediante la Ley 1448 de 2011. Esta es una institución de carácter público del orden nacional adscrito al Departamento de Prosperidad Social (DPS), el cual tienen por objeto recolectar y recobrar información sobre violaciones a los derechos humanos ocurridos durante el conflicto. La información recabada se pone a disposición de las partes interesadas, investigadores y ciudadanos en general, para proporcionar y enriquecer el conocimiento de la historia política y social de Colombia.

El mecanismo más popular en la búsqueda de la verdad son las comisiones de la verdad. Estas son cuerpos de investigación de carácter no judicial o cuasi-judiciales que tienen como propósito principal investigar e informar sobre pasados abusos, en un intento de comprender el alcance y los patrones de violaciones pasadas, así como sus causas y consecuencias. Las comisiones de la verdad son cuerpos temporales, creados por el Estado o una organización gubernamental internacional para el reconocimiento y condena públicos de los perpetradores sin pasar por un juicio.

Las comisiones son cruciales para la reconciliación y la sanación individual y social; ayudan a una sociedad a comprender y reconocer una historia en disputa o denegada, llevar las voces y las historias de las víctimas al público en general y evitar nuevos abusos. Las comisiones de la verdad pueden ser de naturaleza local o nacional. Pueden llevar a cabo investigaciones y audiencias, identificar a las personas e instituciones responsables de las violaciones, pero generalmente no tienen competencia para castigar. Las comisiones de la verdad finalizan con un informe que incluye recomendaciones sobre políticas y enjuiciamientos (UN-IDDRS, 2014, p. 281).

Las sanciones no necesariamente tienen que ser intra-murales para ser efectivas. El mero hecho de que los nombres de las personas que come- 
tieron violaciones graves de derechos humanos estén incluidos en el informe final de una comisión de la verdad constituye una sanción social muy fuerte.

Otras ventajas de las comisiones de la verdad en relación con los tribunales son que sus investigaciones son más rápidas, atienden un mayor número de casos, son compatibles con los juicios y contribuyen a establecer la responsabilidad colectiva de la guerra. Además, las comisiones de la verdad son una verdadera fuerza motriz para el cambio por medio de las recomendaciones contenidas en sus informes finales (Minow et al., 2011, p.121).

En El Salvador, por ejemplo, la implementación de reformas judiciales, incluida la destitución de jueces del Tribunal Supremo y la creación de un nuevo Código de Procedimiento Penal, fueron el resultado de la comisión de la verdad (Ndulo \& Duthie, 2009, p.267).

Conocer la verdad lleva a lo que Sarkin (2012, p.92) ha llamado curación cognitiva. Según el autor, obtener información sobre el contexto político en el que ocurrieron los crímenes individuales y detalles específicos sobre el destino de las víctimas individuales aporta beneficios significativos para su proceso de curación porque elimina la incertidumbre y la sensación de aislamiento que a menudo acompaña al continuo estrés psicológico.

\section{Riesgos de las comisiones de la verdad}

Pese a todos los beneficios antes señalados, las comisiones de la verdad presentan varios limitantes que es preciso considerar a fin de trazarse metas realistas y no crear entre la población, en especial entre las víctimas, expectativas más allá de lo factible.

Aunque las comisiones de la verdad pueden manejar un mayor número de casos que los juicios, el número de participantes en cualquier caso sigue siendo limitado. No todas las personas intervinientes en un conflicto pueden participar en las comisiones de la verdad; por lo tanto, generalmente en ellas se da prioridad a las narrativas de determinado tipo de víctimas, a las víctimas que están organizadas y que han logrado mayor visibilidad en muchos casos gracias a ONGs. 
Por otro lado, Theidon (2015) critica que en Colombia las narraciones del conflicto se han escrito principalmente a partir de las voces de los altos mandos de los grupos paramilitares y guerrilleros, mientras que las voces de los combatientes de bajo nivel han estado ausentes. La autora insiste en la necesidad de escuchar el relato de las víctimas y los perpetradores, y de aquellos que permean las categorías para construir salidas a la violencia.

La cara pública de los paramilitares y los grupos guerrilleros son los oficiales de alto rango que han rendido "confesiones" con la esperanza de evitar la extradición o han dominado a los medios con sus muertes. Ausentes de la esfera pública están las historias de los "combatientes ordinarios" que son actores clave en la reconstrucción o debilitamiento de la convivencia. (Theidon, 2015, p. 323)

En la misma línea, Minow et al. (2011, p.125) reconocen que las comisio- nes de la verdad, en sus esfuerzos por animar a las víctimas a declarar, a menudo no otorgan a los acusados el derecho de confrontar o interrogar a sus acusadores. Otro riesgo que presentan las comisiones de la verdad es el establecimiento de jerarquías entre las víctimas, el privilegio de algunas áreas de violencia sobre otras, y la prevalencia de algunos aspectos del pa- sado sobre otros. La gran cantidad de víctimas y eventos violentos ocurri- dos durante el conflicto, especialmente cuando los conflictos fueron muy prolongados, hacen que las comisiones de la verdad no puedan abordar cada violación en particular, de modo que solo se aborden los casos más importantes. En ese caso, las comisiones pueden convertirse en otro me- canismo de ocultamiento y opresión.

El objetivo perseguido por las comisiones de la verdad, más allá de aclarar crímenes individuales, es exponer los patrones macro de la violencia: las causas, los actores, los métodos y los objetivos del conflicto. Para este propósito, las comisiones de la verdad deben generar espacios donde se escuchen diferentes voces. En el marco de estas comisiones, también debe revelarse el papel desempeñado por las élites locales y nacionales, los grandes empresarios y los líderes políticos en la prolongación del conflicto. Finalmente, las comisiones de la verdad también deberían documentar los actos de resiliencia, heroísmo y humanidad que tuvieron lugar en medio 
del horror para enseñar a las nuevas generaciones que, incluso en los peores momentos de la guerra, es posible encontrar otra manera de enfrentar los problemas diferentes de la violencia.

\section{El papel de las comisiones de la verdad en la reintegración de ex- combatientes}

El IDDRS (2014) observa que las comisiones de la verdad pueden ayudar a romper representaciones rígidas de las víctimas y los perpetradores per- mitiendo a los excombatientes contar sus propias historias de victimiza- ción y explorando e identificando las raíces de un conflicto violento. Con respecto a las reparaciones, advierte que la provisión de compensaciones para las víctimas puede contribuir al programa de reintegración redu- ciendo el resentimiento que las víctimas y las comunidades puedan sentir después de un conflicto armado.

También alienta tanto al DDR como a los actores de la justicia transicional a trabajar juntos en una estrategia que atienda las necesidades de los niños y las mujeres asociados con los grupos armados. Con respecto a la reforma institucional, la norma sugiere que excluir del servicio público a quienes cometieron graves violaciones de derechos humanos es fundamental para lograr la paz y la reconciliación.

En términos sociales, la reintegración busca que los excombatientes reduzcan su contacto y confianza en las redes de las milicias y mejoren su interacción con las comunidades y la familia (Torjesen, 2013, p. 4). Una comprensión integral del aspecto social de la reintegración incluye medidas de justicia restaurativa tales como comisiones de la verdad y rituales comunitarios de perdón. También se ha argumentado que la reintegración social solo puede tener lugar después de que los perpetradores hayan sido castigados por sus crímenes. En el contexto de la justicia transicional, estos castigos no necesariamente implican la privación efectiva de la libertad.

La aceptación de los excombatientes por parte de la comunidad a menudo está condicionada por su participación efectiva en la construcción de la paz, que se manifiesta a través de su contribución a las comisiones de la verdad o actividades históricas de construcción de la memoria. En este sentido, la participación de excombatientes en procesos de desminado 
humanitario o erradicación manual de cultivos ilícitos son ejemplos de actividades restaurativas que los combatientes desmovilizados puedenllevar a cabo. Igualmente, la dimensión social de la reintegración dependerá de la cosmovisión y la cultura de las comunidades receptoras. En muchos casos, la purificación y los ritos de curación u otros actos religiosos de contrición y penitencia son una condición necesaria para que las comunidades abran sus puertas a los excombatientes.

En el mismo sentido, la agenda de las organizaciones internacionales que financian los procesos de DDR y JT determina su énfasis. Por ejemplo, la política de justicia transicional puede tener un énfasis en la verdad o en las reparaciones dependiendo de la agenda de los donantes. Con respecto al DDR, el proceso de reintegración puede tener un enfoque más individual o comunitario, o puede enfatizar en proyectos productivos o en educación dependiendo del interés de los patrocinadores del programa. Para evitar que el DDR y la JT sean guiados internacionalmente es necesario que el gobierno asuma un papel de liderazgo en la financiación del posconflicto.

\section{Participación de los menores soldados en comisiones de la verdad}

La comunidad, las víctimas y los niños soldados pueden necesitar el reco- nocimiento de su responsabilidad para lograr una auténtica reintegración y reconciliación. Un mecanismo de responsabilidad para los niños comba- tientes sin tener que pasar por los tribunales y la cárcel son las comisiones de la verdad. Promueven la investigación de los abusos contra los derechos humanos, recopilan testimonios de los perpetradores, las víctimas y el pú- blico en general.

Las comisiones de la verdad buscan establecer la responsabilidad individual así como la responsabilidad institucional, pero no para castigar. El objetivo principal de estas comisiones es lograr la reconciliación y la reparación a través de una comprensión amplia del conflicto, sus actores y sus causas. El resultado del trabajo de las comisiones es un informe público con la verdad del conflicto y una serie de recomendaciones para evitar la recurrencia de la violencia pasada. 
En un primer momento, se consideró que la participación de los niños soldados en las comisiones de la verdad iba en contra de su interés superior. Por esta razón, las Comisiones de Verdad y Reconciliación de Sudáfrica no tomaron testimonios de personas menores de dieciocho años. Los adultos podían, sin embargo, relatar sus experiencias como niños soldados. La Comisión de la Verdad y la Reconciliación de Sierra Leona (TRC) fue la primera comisión de la verdad que incluyó las declaraciones de los niños en audiencias cerradas y temáticas.

Más de trescientos niños soldados y víctimas de crímenes cometidos por niños rindieron declaraciones ante la comisión. Como resultado, la Comisión de Derechos Humanos de Sierra Leona produjo un informe oficial detallado, que dedicó una sección a tratar el tema de los niños en el conflicto armado. La narrativa utilizada por el informe estuvo impregnada por el enfoque principal de la incapacidad y la victimización de niños combatientes. No obstante, el informe también presenta el papel que desempeñaron como perpetradores y su participación en graves abusos contra los derechos humanos contra la población civil (Drumbl, 2012, pp. 181182).

El Informe TRC de Sierra Leona hizo hincapié en la inmadurez, maleabilidad y vulnerabilidad de los niños; su susceptibilidad a la manipulación; así como su deseo de "complacer a sus mayores". En última instancia, e invocando presiones psicológicas y ambientales, el Informe TRC de Sierra Leona dudaba de que los niños tuvieran capacidad. (Drumbl, 2012, p.183)

La TRC de Sierra Leona adoptó la posición 18 directa que prevalece en el derecho internacional y en particular en el Estatuto de Roma de la Corte Penal Internacional que considera que los niños menores de esa edad no tienen la capacidad legal para ser responsables de sus acciones. En consecuencia, los niños fueron tratados como testigos independientemente de si habían perpetrado violaciones de los derechos humanos.

Su participación fue completamente voluntaria y confidencial. Se requirió el consentimiento informado de los padres o tutores de los niños. Los testimonios de los niños se presentaron en presencia de un trabajador social de confianza (Drumbl, 2012, p.184). 
La Comisión de la Verdad y la Reconciliación de Liberia celebró varias audiencias regionales y mesas redondas con niños. La participación de los niños fue voluntaria y condicionada al consentimiento informado de sus padres o tutores. El UNICEF fue uno de los principales asociados de la comisión en este sentido. En su informe final, la comisión reconoció la doble condición que los niños tuvieron durante el conflicto como víctimas y perpetradores. Sin embargo, la designación de perpetrador se disipó por el énfasis dado a la capacidad disminuida de los niños y la naturaleza forzada de su reclutamiento.

También recomendó la exclusión de todos los niños de la jurisdicción de la Corte Penal Extraordinaria basada en la práctica común de los tribunales internacionales para excluirlos del enjuiciamiento por violaciones de graves de derechos humanos y la restricción del Estatuto de Roma a la edad legal de rendir cuentas a los 18 (Drumbl, 2012, pp. 185-187).

La participación de los niños en las comisiones de la verdad ayuda a entender más su doble papel como víctimas y perpetradores en el conflicto y a desarrollar recomendaciones. Sus declaraciones pueden servir no solo para recopilar sus experiencias como malhechores sino también sus experiencias positivas de supervivencia y resiliencia.

Las comisiones de la verdad, junto con los mecanismos informales de reconciliación basados en la cultura, pueden ayudar a los niños soldados a reconectarse con sus comunidades, especialmente si tienen componentes dirigidos a esta población. Brindar a los sobrevivientes de la guerra, incluidos los niños soldados, un espacio donde puedan contar historias entre ellos que quizás no estén dispuestos a compartir con un público más amplio, puede lograr efectos catárticos y curativos. Un espacio donde las víctimas pueden hablar entre ellas y apoyarse mutuamente puede promover la reconciliación personal.

Como parte de la reconciliación, los sobrevivientes de la violencia -incluidos los niños soldados y otros niños afectados- deben comprender qué les sucedió. Aunque experimentaron un trauma personal, su experiencia fue en el contexto de una violencia política mayor que muchas víctimas no comprenden por completo. Esto es especialmente cierto cuando las víctimas son niños, personas elegidas al azar, o utilizados como meras fichas de fuerzas políticas (Sarkin, 2012, pp. 89-92). 


\section{Reconciliación: la meta conjunta}

Tradicionalmente, el diseño y la implementación de la política de justicia transicional se han fundado en el supuesto de que las víctimas y los ex- combatientes son esencialmente grupos sociales diferentes e incluso opuestos.

Contrario a esto, Nussio, Rettberg y Ugarriza (2015, pp. 353-354) encontraron que las diferencias en las actitudes entre víctimas y no víctimas hacia varios aspectos de la justicia transicional tales como juicios penales, establecimiento de la verdad, memoria histórica y reparaciones, son leves.

Los autores sugieren además que la coincidencia de las víctimas y las actitudes de la población general hacia la justicia transicional en las políticas y debates de justicia transicional son una evidencia de la importancia que las medidas de justicia transicional tienen para la sociedad en general, y no solo para una parte de ella.

La Reintegración y la Justicia Transicional comparten un interés en la idea de la reconciliación, un término caracterizado por la discrepancia en su significado y en los medios para lograrlo. El concepto de reconciliación se puede abordar desde dos perspectivas. Por un lado, la reconciliación puede entenderse como un proceso principalmente interpersonal entre la víctima y el victimario, a menudo con una connotación espiritual o psicológica.

Desde esta perspectiva, la reconciliación se produce a nivel individual y consiste en el arrepentimiento y la penitencia del perpetrador, por un lado, y la comprensión y el perdón de la víctima en el otro lado. Sin embargo, las víctimas no pueden ser forzadas a perdonar a sus victimarios. La forma en que cada individuo trata su dolor es particular. Como Minow et al. observa: "el perdón debe ser una opción para los individuos, solo una opción, el poder de perdonar debe estar inextricablemente ligado al poder de elegir no hacerlo" (2011, p.88). Exigir el perdón de las víctimas que no pueden perdonar puede constituir una revictimización.

Desde este enfoque, el centro de la reconciliación es precisamente el daño emocional causado más que el sustrato material del conflicto, de ahí que con frecuencia el tema de la reconciliación tenga un enfoque predominantemente religioso. 
Por esta razón, en muchos casos, se busca la reconciliación a través de terapias psicológicas y programas espirituales dirigidos al manejo del trauma tanto para los excombatientes como para las víctimas. Este enfoque sugiere que lo que las víctimas requieren para poder perdonar es suficiente apoyo emocional y espiritual. Una crítica a esta postura es que les da a las víctimas el peso de la reconciliación igualando la reconciliación con el perdón y el olvido.

Por otro lado, la reconciliación puede referirse a un proceso más amplio cuyo enfoque no reside en la víctima y el perpetrador individualmente considerados, sino en la sociedad en su conjunto. Desde esta perspectiva, la reconciliación se logra a través de intervenciones a nivel macro tales como comisiones de la verdad, juicios transicionales, sistemas de reparación, medidas de lustración y reformas institucionales, de allí su enfoque político (Prieto, 2012, p.531).

Esto no es, en mi opinión, la forma en que la reconciliación o la terapia deberían funcionar. "Psicologizar" problemas que tienen sus raíces en la desigualdad, la violencia política y el miedo constante no permite que los hacedores de política pública aborden las dinámicas sociales más amplias que alimentan el conflicto. Claramente, la guerra no es estrictamente un problema médico o psicológico. Ciertamente se derrama sangre; hay víctimas y muertes. Sin embargo, tanto los orígenes como la resolución del conflicto armado van más allá de los límites del modelo médico o los conceptos clínicos de "recuperación". (Theidon, 2015, p 336)

En un estudio realizado por Prieto (2012), la mayoría de las víctimas par- ticipantes declararon que no habían encontrado a sus autores en sus luga- res de residencia. Del mismo modo, la mayoría de los excombatientes ma- nifestaron no haberse topado con ninguna de sus víctimas en los lugares donde viven.

Esto se debe, por una parte, al hecho de que la mayoría de las personas desmovilizadas llevan a cabo su proceso de reintegración en lugares distintos de aquellos a donde operaron. Por otro lado, en un conflicto como el colombiano, donde no ha habido una comisión de la verdad, muchos 
crímenes no han sido esclarecidos, muchas víctimas desconocen los rostros de sus perpetradores y los perpetradores no recuerdan las caras de todas sus las víctimas, la reconciliación interpersonal y el perdón a menudo no son posibles.

En estos casos, tanto las disculpas como el perdón se esperan del Estado y de la sociedad como un todo, pero no de individuos particulares. Las víctimas aguardan una justa compensación y garantía de no repetición por parte del Estado, mientras que los excombatientes esperan de éste el perdón y una nueva oportunidad. En este sentido, un programa de reparación integral y las disculpas públicas del Estado, así como amnistías (perdón político) y la implementación de un programa de reintegración, son manifestaciones de reconciliación política. La reconciliación social, por otro lado, es un proceso mucho más complejo y de largo plazo que, sin embargo, puede ser potencializado por la reconciliación política.

Estos dos enfoques de la reconciliación no son necesariamente competitivos sino complementarios. De hecho, la reconciliación se lleva a cabo tanto mediante intervenciones religiosas como políticas.

La separación entre DDR y JT tiene muchos aspectos negativos para la construcción de la paz. Por ejemplo, debido a esta separación, los recursos del post-conflicto no se utilizan de manera eficiente, y solo se conoce una parte de la verdad.

También contribuye al etiquetamiento (víctima-perpetrador), lo que dificulta la reconciliación y fomenta la estigmatización. De hecho, aunque la población víctima del conflicto y gran parte de la población desmovilizada tiene características y necesidades comunes, no se abordan conjuntamente.

Ambos grupos tienen, por ejemplo, la necesidad de atención psicosocial, educación y capacitación para el trabajo; sin embargo, ambas poblaciones son atendidas por diferentes autoridades bajo diferentes programas. El documento sugiere un enfoque estructural del DDR basado en la articulación de programas de reintegración con mecanismos más amplios de justicia transicional, como es el caso de las comisiones de la verdad. 


\section{Conclusiones}

El derecho a la verdad ha sido pensado fundamentalmente como un dere- cho de las víctimas; sin embargo, el derecho a la verdad es un derecho de la sociedad como un todo.

La comisión de la verdad es un espacio en el que todos los actores de la guerra: víctimas, perpetradores y el resto de la sociedad que, por miedo o indiferencia, permitieron que el conflicto se prolongara en el tiempo, tienen el deber moral de participar en la construcción de la memoria colectiva de dicho conflicto. La comprehensividad de la comisión de la verdad y su facultad de recopilar todas las voces hacen de este mecanismo un elemento clave de la reconciliación y un punto de convergencia entre DDR y TJ.

En Colombia, el DDR intersecta con la justicia transicional en varios aspectos. En el tema de reparación, ambos campos confluyen al existir la obligación de los grupos desmovilizados de devolver todos los bienes obtenidos ilícitamente para compensarlas. Asimismo, convergen en el tema de la verdad ya que los desmovilizados con anterioridad a los acuerdos de paz deben participar en los "acuerdos de verdad" previstos en la Ley 1424 de 2010 y los de las FARC en la comisión de la verdad. También convergen en el aspecto de justicia al tener los máximos responsables de graves violaciones a los derechos humanos a comparecer ante jurisdicción de justicia y paz, en el caso de las AUC, y jurisdicción especial para la paz, en el caso de las FARC. Sin embargo, hay otros aspectos en los que se precisa una mayor articulación entre los dos campos, así como en la atención de ambas poblaciones para superar su estado de vulnerabilidad.

Tanto el DDR como la JT tienen el mismo fin último: lograr la paz y la reconciliación. Tradicionalmente, se ha creído que la paz es la ausencia de conflicto armado, el cese el fuego o, en otras palabras, la paz negativa; por lo tanto, DDR se ha asociado generalmente con la paz, mientras que JT y sus diferentes dimensiones (verdad, justicia, reparación y no repetición) o paz positiva, se han asociado con la reconciliación. Sin embargo, los excombatientes son un elemento esencial para hacer posible la justicia transicional. La comisión de la verdad no tendría sentido sin la participación de excombatientes. La reparación no estaría completa si el combatiente desmovilizado no pide perdón, contribuye a establecer el paradero de los 
desaparecidos o no devuelve los bienes obtenidos ilegalmente. Finalmente, las garantías de no repetición no son efectivas si el Estado no adopta medidas para fortalecer su presencia en todo el territorio y su monopolio de las armas.

\section{Referencias}

Benavides, F. (2011). Justicia en épocas de transición: conceptos, modelos, debates, experiencias. Barcelona: Institut Català International per la Pau.

Drumbl, M. (2012). Reimagining Child Soldiers in International Law and Policy. Oxford: Oxford University Press.

Grasa, R. y Mateos, O. (2014). Guía para trabajar en la construcción de la pa\%: Quién es y qué supone la construcción de la paz. Bogotá: Instituto Catalán Internacional para la Paz \& Cámara de Comercio de Bogotá.

Minow, M.; Crocker, D.; y Mani, R. (2011). Justicia Transicional. Bogotá: Siglo del hombre editores.

Ndulo, M. y Duthie, R. (2009). "The Role of Judicial Reform in Development and Trasitional Justice". In: De Greiff, Pablo and Duthie, Roger (Eds). Transitional Justice and Development. Making Connections. New York: International Center for Transitional Justice.

Nussio, E.; Rettberg, A. y Ugarriza, J. (2015). "Victims, nonvictims and their options on transitional justice: Findings from the Colombian case". International Journal of Transitional Justice. Vol. 9, 336-354.

Prieto, J. D. (2012). Together after War While the War Goes On: Victims, ExCombatants and Communities in Three Colombian Cities. The International Journal of Transitional Justice, Vol. 6, 525-546.

Restrepo, E. (2012). "Transitional Justice without a compass: Paramilitary demobilization in Colombia". In Popovski, Vesselin \& Serrano, Mónica (Eds.). After oppression: Transitional justice in Latin America and Eastern Europe. New York: United Nations University Press.

Sarkin, J. (2012). "Integrating Transitional Justice and Disarmament, Demobilisation and Reintegration". In Derluyn et al (Eds.). Rehabilitation, Reintegration and Reconciliation of War-Affected Children. Cambridge: Intersentia.

Shibuya, E. (2012). Demobilizing Irregular Forces. W ar and Conflict in the Modern World. Cambridge: Polity Press. 
Sriram, Ch. L. y Herman, J. (2009). "DDR - and Transitional Justice: Bridging the Divide?" Conflict, Security \& Development 9, no. 4, 455-74.

Teitel, R. (2003). Genealogía de la justicia transicional. En: Harvard HumanRights Journal, Vol. 16, spring 2003, Cambridge, MA, pp. 69-94.

Theidon, K. (2015). "Pasts Imperfect: Talking about Justice with Former Combatants in Colombia". In: Genocide and Mass Violence Memory, Symptom, and Recovery. Hinton, Devon \& Hinton, Alexander (Eds). Cambridge: Cambridge University Press.

Torjesen, S. (2013). "Towards a theory of ex-combatant reintegration." Stability: International Journal of Security \& Development, 2(3): 63, pp. 1-13.

United Nations, Operational Guide to the Integrated Disarmament, Demobilization and Reintegration Standards (IDDRS), 2014.

Uprimny, R.; Saffon, M.; Botero, C. y Restrepo, E. (2006). ¿Justicia transicional sin transición? Verdad, justicia y reparación para Colombia. Bogotá: Ediciones Antropos. 